
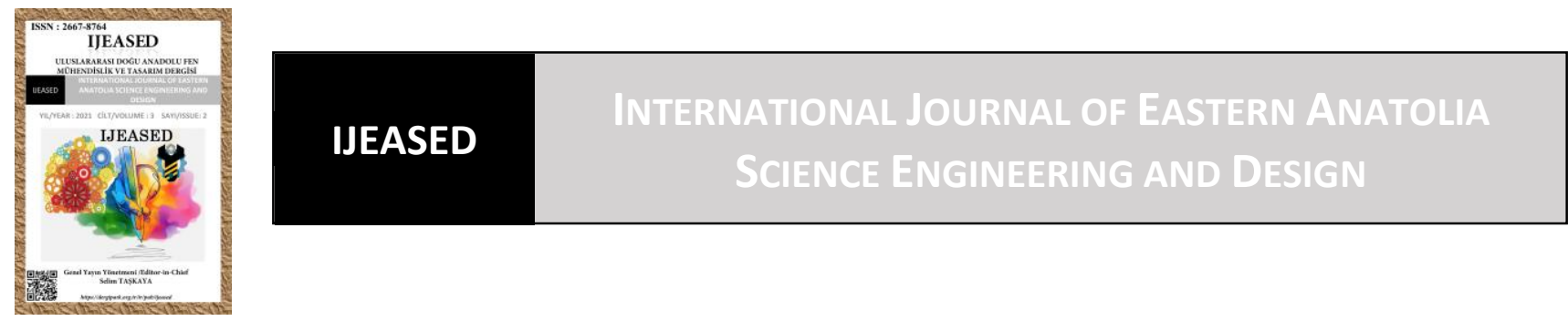

\author{
Uluslararası Doğu Anadolu Fen Mühendislik ve Tasarım Dergisi \\ ISSN: 2667-8764, 3(2), 376-387, 2021 \\ https://dergipark.org.tr/tr/pub/ijeased
}

Araştırma Makalesi / Research Article

Doi: $10.47898 /$ ijeased.981248

\title{
Antalya İli Kaş İlçesi Örneğinde Alan Kullanım / Arazi Örtüsü Değişim Tespiti
}

\author{
Veli SÜNBÜL ${ }^{1}$, Ebru ERSOY TONYALOĞLU ${ }^{2 *}$
}

${ }^{1}$ Aydın Adnan Menderes Üniversitesi, Peyzaj Mimarlığı Bölümü, Ziraat Fakültesi, Aydın, 09100, Türkiye.

${ }^{2}$ Aydın Adnan Menderes Üniversitesi, Peyzaj Mimarlığı Bölümü, Ziraat Fakültesi, Aydın, 09100, Türkiye.

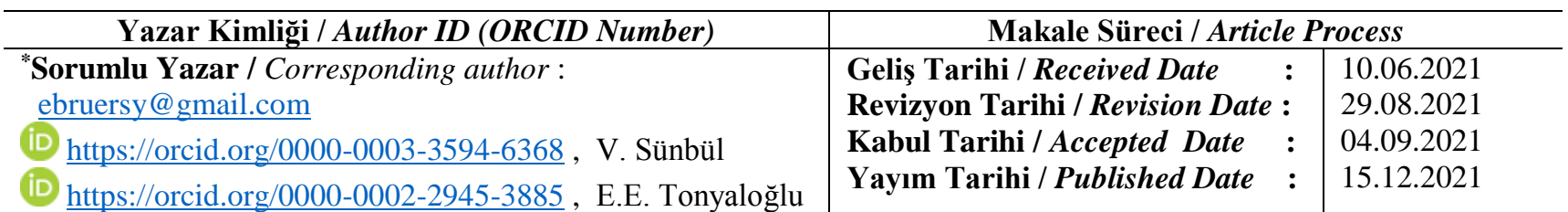

Alıntı / Cite : Tonyaloğlu Ersoy, E., Sünbül, V., (2021). Antalya İli Kaş İlçesi Örneğinde Alan Kullanım / Arazi Örtüsü Değişim Tespiti, Uluslararası Doğu Anadolu Fen Mühendislik ve Tasarım Dergisi, 3(2), 376-387.

\section{Özet}

Bu çalışmanın amacı Türkiye'nin önemli bir turizm ve tarımsal üretim alanı olan Antalya ili Kaş ilçesinde 2000 ve 2020 yılları arasında alan kullanım / arazi örtüsünde (AKAÖ) meydana gelen değişim ve dönüşümlerin tespit edilmesidir. Çalışmada 2000 tarihli Landsat 7 ETM+ ve 2020 tarihli Landsat 8 OLI uydu görüntüleri kullanılarak, ArcGIS 10.5 yazılımında elle sayılaşlaştırma yöntemi ile AKAÖ haritaları elde edilmiştir. AKAÖ değişim tespitinde FRAGSTATS v4.2 yazılımı ile sınıf düzeyinde 5 peyzaj metriği hesaplanmıştır. AKAÖ’nde meydana gelen dönüşümler ise ENVI 5.1 yazılımı Thematic Change Wofkflow aracı kullanılarak hesaplanmıştır. Sonuç olarak, 20 yıllık zaman periyodunda çalışma alanında yapısal alanların kıyılara yakın bölgeler başta olmak üzere yaklaşık 2.5 kat arttığı, sera üretiminin ise çalışma alanında önemli bir ekonomik kaynak olarak kullanılmaya başlandığı tespit edilmiştir. Ayrıca, maden çıkarım sahalarında görülen 4 kat artış ise, orman alanlarında kayıplara neden olurken, bitki örtüsü az yada hiç olmayan alanlardan sera üretim alanlarına ve çıplak yüzeylere dönüşümler yaşanmıştır.

Anahtar Kelimeler: AKAÖ, Değişim, Kaş, Landsat, Peyzaj metrikleri.

\section{Determination of Land Use / Land Cover Change in the Case of Kaş District of Antalya}

\begin{abstract}
The aim of this study is to determine the changes and transformations in the land use / land cover (LULC) between 2000 and 2020 in Kaş district of Antalya province, which is an important tourism and agricultural region in Turkey.


Sünbül, V. ve Tonyaloğlu Ersoy, E., Uluslararası Doğu Anadolu Fen Mühendislik ve Tasarım Dergisi / International Journal of Eastern Anatolia Science Engineering and Design (IJEASED)

(2021) 3(2): 376-387

LULC maps were derived by manual digitization method in ArcGIS 10.5 software using Landsat 7 ETM+ and Landsat 8 OLI satellite images dated 2000 and 2020, respectively. 5 landscape metrics at the class level of the FRAGSTATS $v 4.2$ software were calculated to detect the change in LULC. The transformations that occurred in the LULC were calculated using the ENVI 5.1 software Thematic Change Wofkflow tool. As a result, it has been determined that the built-up areas have increased by approximately 2.5 times, especially in the areas close to the coasts, and greenhouse production has started to be used as an important economic resource in the study area during 20-year period. Also, whilst the 4-fold increase in the mining areas caused losses in forest areas, there were transformations from the areas with little or no vegetation to greenhouse production areas and bare surfaces.

Keywords: LULC, Change, Kaş, Landsat, Landscape metrics.

\section{Giriş}

Dünya çapında peyzajlar üzerinde artan antropojenik faaliyet ve baskılar, küresel ekosistemlerin yapıları ve işleyişleri üzerinde birçok değişim ve olumsuz etkiye neden olmaktadır (Lambin ve ark., 2001). Özellikle karasal ekosistemler üzerinde en görünür insan kaynaklı değişimlerden birisinin yerel, bölgesel ve küresel ölçeklerde yaşanabilen ve peyzajları büyük ölçüde etkileyen alan kullanımı ve arazi örtüsü (AKAÖ) değişimleri olduğu düşünülmektedir (Meyer ve Turner, 1994; Kesgin ve Nurlu, 2009; Atak Kesgin, 2020). Uzun vadede insanlığın gelişiminin de bir sonucu olarak, tüm dünyada zaman içinde arazi yüzeyinin büyük bölümü doğal bitki örtüsünden insanların çeşitli ihtiyaçlarına yönelik farklı alan kullanımlarına dönüştürülmüştür. Arazi örtüsünde yaşanan bu uzun vadeli dönüşüm ve değişimler, yerel ve ekosistemleri etkileyerek, iklim değişikliği, biyolojik çeşitliliğin bozulması, ve biyojeokimyasal ve hidrolojik döngülerin küresel ölçekte dalgalanması gibi çeşitli çevre sorunlarının yaşanmasına neden olmuştur (Ito ve ark., 2004; Atak Kesgin, 2020).

Uzaktan algılama (UA) ve Coğrafi Bilgi Sistemleri (CBS) gibi coğrafi teknikler, bir dizi mekansal ve zamansal ölçekte AKAÖ değişimlerinin belirlemesi ve izlenmesinde en önemli ve güçlü araçlar arasında değerlendirilmektedir (Kesgin ve Nurlu, 2009; Lu ve ark., 2011). UA teknolojisi yardımıyla geniş alanlara ilişkin uygun maliyetli veriler sağlanabildiği için, uydu verileri birçok ülkede çevresel değişimlerin saptanmasında önemli bir veri kaynağı olarak değerlendirilmektedir (Liu ve Yang, 2015). Özellikle Uluslararası Jeosfer-Biyosfer Programı (International Geosphere-Biosphere Project/IGBP) ve Uluslararası İnsan Boyutları Programı (International Human Dimensions Programme/IHDP) 1995 yılında AKAÖ değişim planını başlatmasından iitibaren, AKAÖ değişimlerinin haritalanması ve izlenmesinde CBS ile multispektral ve multitemporal uzaktan algılanan verilerin kullanımı dünyanın farklı yerlerindeki araştırmalar için ana odak noktası haline gelmiştir (Guan ve ark., 2011; Corner ve ark., 2013). Bununla birlikte AKAÖ deseninin peyzajların işleyiş ve fonksiyonları üzerinde de önemli bir 
katkısı olduğu düşünülmektedir (Botequila ve ark., 2006). Dolayısıyla AKAÖ deseni ile bu desenle ilişkili işlevlerin ve süreçlerin analiz edilmesi büyük önem taşımaktadır. Ayrıca, her ne kadar UA verileri ve CBS yardımıyla kentsel alanlardaki AKAÖ değişimlerini değerlendirmek için sayısal birçok çalışma gerçekleştirilmiş olsa da, peyzaj ekolojisinde yaygın olarak kullanılan peyzaj metrikleri ile insan kaynaklı faaliyetler sonucu oluşan değişimlerin belirlenmesi ve değerlendirmesi için sayısal bilgilerin elde edilip peyzaj işlevleri ile ilişkilendirilmesi de büyük önem taşımaktadır. $\mathrm{Bu}$ kapsamda peyzaj metriklerinin kullanımı tüm dünyada yaygın bir yöntem oluşturmaktadır (McGarigal ve Marks, 1995; Wang ve ark., 2013).

Günümüzde AKAÖ deseninin haritalanması, karakterize edilmesi ve zaman içinde yaşanan değişimlerin tespit edilebilmesine yönelik olarak farklı mekansal ve zamansal çözünürlüklerde veri sağlayan birçok uydu görüntüsü bulunmasına karşın, AKAÖ’deki insan kaynaklı değişimlerin tespiti ve izlenmesi genellikle gelişmekte olan ülkelerde yetersiz düzeydedir. Ancak AKAÖ değişimlerinin tespit edilip izlenebilmesinin tüm ülkelerde, çeşitli doğal ve kültürel kaynakların doğru ve akılcı yönetimi ve kullanımı için gerekli olan insan ve doğa olayları arasındaki ilişkilerin ve etkileşimlerin daha iyi anlaşılması için temel bilgi sağladığı da aşikardır (Lu ve ark., 2004; Kesgin ve Nurlu, 2009). Her ne kadar ülkemizin çeşitli bölgelerinde AKAÖ değişim analizleri gerçekleştirilmiş olsa da, peyzaj ekolojisi perspektifinden kentsel ve/veya kent çevresindeki yerleşim alanlarındaki AKAÖ değişim ve dönüşümlerinin ayrıntılı değerlendirmesi ve peyzaj işlevleri ile ilişkilendirilmesi hala kısıtlı bir alan olarak karşımıza çıkmaktadır. Özellikle turizm, yapılaşma ve tarımsal faaliyetlerin etkisi altında olan peyzajlarda değişim ve dönüşüm dinamiklerinin anlaşılması hem insan yaşamı ve doğal çevre açısından önemli olan süreçlerin birbirileri ile ilişkilendirilerek değerlendirilmesi hem de peyzaj planlama kararlarına ışık tutulması açısından büyük önem taşımaktadır. Bu kapsamda, bu çalışma ile günümüzde önemli bir turizm ve tarımsal üretim alanı olan Antalya ili Kaş ilçesinde 2000 ve 2020 yılları arasında AKAÖ deseninde ve temel peyzaj işlevlerinde meydana gelen değişim ve dönüşümlerin belirlenmesi amaçlanmıştır.

\section{Materyal ve Metot}

\subsection{Materyal}

Bu çalışmanın ana materyalini örnek çalışma alanı olan Antalya ili, Kaş ilçesi oluşturmaktadır (174453.07ha). Antalya'nın batısında yer alan Kaş ilçesi önemli bir turizm merkezi ve sera üretim alanı olarak dikkat çekmektedir. Kaş ilçesi, Antalya sahillerinde doğal bir liman çevresinde ve vadi 
içinde dar bir topografyada yer almaktadır (Şekil 1). Sahil şeridi uzunluğunun yaklaş1k 90km olduğu Kaş ilçesinin kuzeyinde Elmalı, Doğusunda Finike, kuzey-batısında ise Fethiye ilçeleri yer almaktadır (Akman, 2007). Akdeniz ikliminin hakim olduğu ilçede, yağışlar genellikle Ocak ve Şubat aylarında görülürken, kıyı şeridinde en sıcak zaman dilimi Temmuz ve Ağustos ayları olup, yaz boyunca bu alanlarda yağış alınmamaktadır (Akman, 2007). Maki bitki örtüsünün hakim olduğu Kaş ilçesinde, yabani zeytin örtüsü de yaygın bir şekilde görülmektedir. Kaş ilçesi nüfusunun büyük bir bölümü kırsal alanlarda yaşamakta iken, sadece 15'lik bir oranı ilçe merkezinde yaşamaktadır (Akman, 2007).

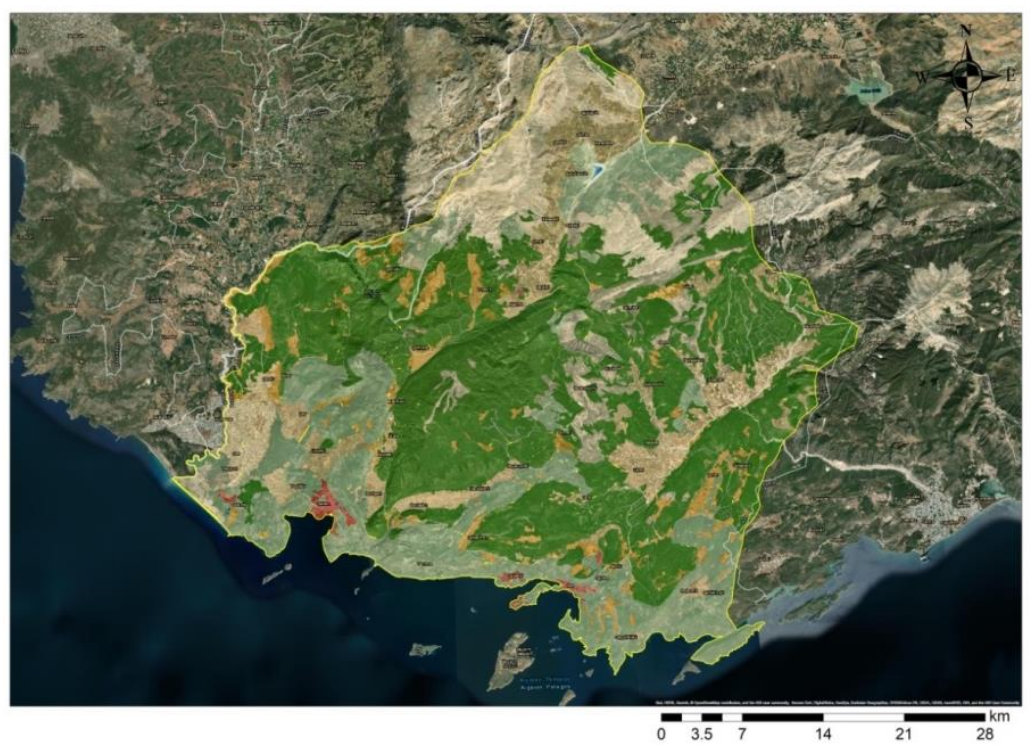

Şekil 1. Çalışma alanı.

Çalışmada kullanılan temel veriler 28.08.2000 tarihli Landsat 7 ETM+ ve ve 27.08.2020 tarihli Landsat 8 OLI uydu görüntülerinden oluşmaktadır. Landsat uydu görüntüleri Amerika Birleşik Devletleri Jeolojik Araştırmalar kurumunun, EarthExplorer ara yüzünden elde edilmiştir (URL-1). Çalışmada AKAÖ sınıflandırmaları ve doğruluk analizleri için ArcGIS 10.5, peyzaj metriklerinin hesaplanması ve yorumlanması için ise FRAGSTATS v4.2 ve Microsoft Excel 2010, ve AKAÖ dönüşümlerinin hesaplanmasında ise ENVI 5.1 yazılımlarından yararlanılmıştır. Ayrıca, sınıflandırmalarda yardımcı veri olarak Google Earth Pro kullanılmıştır.

\subsection{Metot}

Bu çalışmada 28.08.2000 tarihli Landsat 7 ETM+ ve 27.08.2020 tarihli Landsat 8 OLI uydu görüntülerinin 30m yersel çözünürlüklü Blue (Bant 2), Green (Bant 3), Red (Bant 4), NIR (Bant 5) ile $15 \mathrm{~m}$ yersel çözünürlüklü Panchromatic (Bant 8) bantaları kullanılarak ekran sayısallaştırması ile 
AKAÖ haritaları oluşturulmuştur. Öncelikle ArcGIS 10.5 yazılımında 2,3,4 ve 5 bantları birleştirilerek (layer stack) gerçek renkli (true colour) görüntü elde edilmiş, daha sonra 30m yersel çözünürlüklü bu görüntü Bant 8 ile $15 \mathrm{~m}$ yersel çözünürlükte örneklenerek her iki tarihe ait görüntüden elle sayısallaştırma yöntemi ile AKAÖ haritaları elde edilmiştir. Sayısallaştırma işlemi sırasında Landsat uydu verilerinden çıkarılamayan detaylar için Google Earth Pro'dan yararlanılmıştır. Her iki tarih için çalışma alanında 10 farklı AKAÖ sınıfı tanımlanarak haritalanmıştır (Tablo 1).

Tablo 1. Çalışmada belirlenen 2000 ve 2020 y1llarına ait AKAÖ sınıfları ile toplam alanları (ha)

\begin{tabular}{lccc}
\hline \multicolumn{1}{c}{ AKAÖ } & Kisaltma & 2000 Y1lı Alan (ha) & 2020 Y1l Alan (ha) \\
\hline Bitki örtüsü az alanlar & BÖA & 45319.34 & 36131.72 \\
Çılak yüzey & ÇY & 22293.56 & 25543.46 \\
Liman & L & 10.17 & 23.49 \\
Maden sahas1 & MS & 10.76 & 41.63 \\
Orman & O & 78460.07 & 75942.54 \\
Sera alanı & SA & 7722.52 & 22671.88 \\
Su yüzeyi & SY & 72.50 & 72.50 \\
Tarım alanı & TA & 16572.78 & 9088.18 \\
Yapisal alan & YA & 473.45 & 1079.42 \\
Yol & Y & 3517.92 & 3834.95 \\
Liman & L & 10.17 & 23.49 \\
\hline
\end{tabular}

ArcGIS 10.5 yazılımında elde edilen AKAÖ haritalarının doğruluk analizleri 1100 nokta üzerinden hata matrisi yöntemi ile gerçekleştirilmiştir (Congalton ve Green, 2019). Çalışmada, AKAÖ sınıflarında meydana gelen değişimin saptanmasında FRAGSTATS v4.2 yazılımında sınıf düzeyinde 5 peyzaj metriği hesaplanmıştır (Tablo 2).

Tablo 2. Çalışmada kullanılan peyzaj metrikleri (Botequila ve ark., 2006)

\begin{tabular}{llll}
\hline \multicolumn{1}{c}{ Metrik Adı } & \multicolumn{1}{c}{ Birim } & \multicolumn{1}{c}{ Kısaltma } & \multicolumn{1}{c}{ Kullanım Amacı } \\
\hline Toplam yama alanı & ha & CA & Baskınlık, hakimiyet \\
Peyzaj yüzdesi & $\%$ & PLAND & Baskınlık, hakimiyet \\
Parça/yama sayısı & - & NP & Parçalanma \\
Ortalama yama alanı & ha & AREA_MN & NP ile birlikte parçalanma \\
Öklid en yakın komşu mesafesi & m & ENN_MN & Parçalanma, izolasyon \\
\hline
\end{tabular}

Elde edilen peyzaj metriklerine ilişkin sonuçlar Microsoft Excel 2010 yazılımına aktarılarak tablolanmış ve karşılaştırmalı olarak AKAÖ'de meydana gelen değişimler değerlendirilmiştir. Ayrıca AKAÖ haritalarında meydana gelen dönüşümün belirlenebilmesi için ENVI 5.1 yazılımı Thematic Change Wofkflow aracı kullanılmış, sınıflandırma sonrası karşılaştırma tekniği (PostClassificationTechnique) uygulanmıştır ( $\mathrm{Lu}$ ve ark., 2004). Bu yöntemin uygulanması yoluyla 
değişimin meydana geldiği alanlarda -den, -e (-from...-to) değişim / dönüşüm bilgisi elde edilmiştir.

\section{Bulgular ve Tartışma}

Uydu görüntülerinin sınıflandırılması için kullanılan elle sayısallaştırma tekniğinin doğruluğunu sınamak için rasgele 1100 nokta üzerinden hata matrisi yöntemi ile değerlendirilmiştir. Gerçekleştirilen doğruluk analizi sonuçlarına göre 2000 yılı AKAÖ haritasının toplam doğruluğu \%93, kappa değeri 0,90; 2020 yılı AKAÖ haritasının ise toplam doğruluğu \%89, kappa değeri ise 0,85 olarak hesaplanmıştır. 2000 ve 2020 yıllarına ait AKAÖ haritaları Şekil 2'de gösterilmiştir.

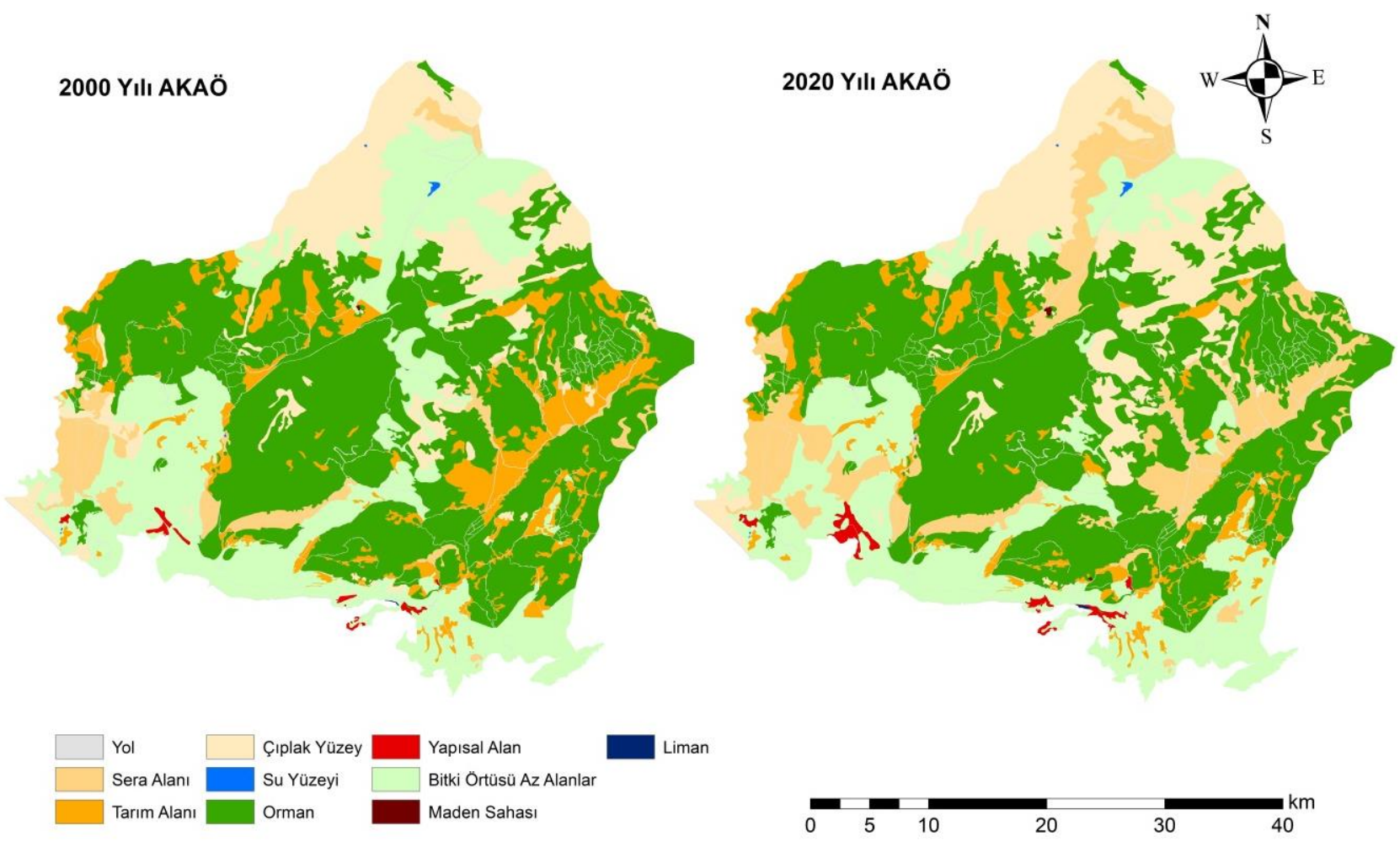

Şekil 2. 2000 ve 2020 yıllarına ait AKAÖ haritaları.

Çalışma alanında 2000 ve 2020 yılları arasında 20 yıllık zamanda meydana gelen değişimleri tespit etmek ve bu değişimlerin sebep olduğu yapısal ve işlevsel süreçleri açıklamak amacıyla hesaplanan 5 peyzaj metriğine ilişkin sonuçlar Tablo 3'te, AKAÖ sınıflarında meydana gelen değişim oranları ise Tablo 4'de verilmişstir.

Tablo 3. 2000 ve 2020 yılı peyzaj metrikleri sonuçları 


\begin{tabular}{lcccccc}
\hline AKAÖ Sınıfi & Y1l & CA & PLAND & NP & AREA_MN & ENN_MN \\
\hline Bitki örtüsü az & 2000 & 45319.34 & 25.98 & 63 & 719.35 & 356.11 \\
alanlar & 2020 & 36131.72 & 20.71 & 61 & 592.32 & 299.51 \\
Çılak Yüzey & 2000 & 22293.56 & 12.78 & 64 & 348.34 & 514.96 \\
& 2020 & 25543.46 & 14.64 & 47 & 543.48 & 523.65 \\
Liman & 2000 & 10.17 & 0.01 & 1 & 10.17 & N/A \\
& 2020 & 23.49 & 0.01 & 1 & 23.49 & N/A \\
Maden Sahas1 & 2000 & 10.76 & 0.01 & 1 & 10.76 & N/A \\
& 2020 & 41.63 & 0.02 & 2 & 20.81 & 22369.71 \\
Orman & 2000 & 78460.07 & 44.97 & 136 & 576.91 & 94.14 \\
& 2020 & 75942.54 & 43.54 & 158 & 480.65 & 96.98 \\
Sera Alanı & 2000 & 7722.52 & 4.43 & 46 & 167.88 & 497.43 \\
& 2020 & 22671.88 & 13.00 & 64 & 354.25 & 200.86 \\
Su Yüzeyi & 2000 & 72.50 & 0.04 & 5 & 14.50 & 5660.85 \\
\multirow{2}{*}{ Tarım Alanı } & 2020 & 72.50 & 0.04 & 5 & 14.50 & 5660.85 \\
& 2000 & 16572.78 & 9.50 & 166 & 99.84 & 301.29 \\
Yapisal Alan & 2020 & 9088.18 & 5.21 & 142 & 64.00 & 409.74 \\
& 2000 & 473.45 & 0.27 & 11 & 43.04 & 1112.57 \\
Yol & 2020 & 1079.42 & 0.62 & 8 & 134.93 & 1374.20 \\
& 2000 & 3517.92 & 2.02 & 23 & 152.95 & 363.01 \\
& 2020 & 3834.95 & 2.20 & 26 & 147.50 & 329.21 \\
\hline
\end{tabular}

Tablo 4. 2000 ve 2020 yılı peyzaj dönüşüm miktarları (\%)

\begin{tabular}{|c|c|c|c|c|c|c|c|c|c|c|c|}
\hline \multirow{2}{*}{\multicolumn{2}{|c|}{$\begin{array}{l}\text { Dönüşümm } \\
(\%)\end{array}$}} & \multicolumn{10}{|c|}{2000 yılı AKAÖ sınıfları } \\
\hline & & $\bar{Y}$ & SA & TA & ÇY & SY & $\mathrm{O}$ & YA & BÖA & MS & $\bar{L}$ \\
\hline \multirow{10}{*}{ 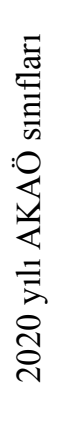 } & & 99.96 & 0 & 0 & 0.32 & 0 & 0.29 & 0 & 0.05 & 0 & 0 \\
\hline & SA & 0 & 99.54 & 48.43 & 2.78 & 0 & 0.74 & 0 & 12.72 & 0 & 0 \\
\hline & TA & 0 & 0.46 & 50.28 & 1.86 & 0 & 0.14 & 0 & 0.43 & 0 & 0 \\
\hline & CY & 0 & 0 & 0.95 & 90.82 & 0 & 0.77 & 0 & 10.06 & 0 & 0 \\
\hline & SY & 0 & 0 & 0 & 0 & 100 & 0 & 0 & 0 & 0 & 0 \\
\hline & $\mathrm{O}$ & 0.04 & 0.00 & 0.16 & 2.66 & 0 & 94.89 & 0 & 1.93 & 0 & 0 \\
\hline & YA & 0 & 0 & 0.19 & 0.40 & 0 & 0 & 99.50 & 1.07 & 0 & 10.09 \\
\hline & BÖA & 0 & 0 & 0 & 1.16 & 0 & 3.17 & 0.50 & 73.69 & 0 & 4.36 \\
\hline & MS & 0 & 0 & 0 & 0.00 & 0 & 0.01 & 0 & 0.05 & 100 & 0 \\
\hline & $\mathrm{L}$ & 0 & 0 & 0 & 0 & 0 & 0 & 0 & 0.00 & 0 & 85.55 \\
\hline \multirow{2}{*}{\multicolumn{2}{|c|}{$\begin{array}{l}\text { Sinıf } \\
\text { toplamı } \\
\text { Sınıf } \\
\text { değişimi }\end{array}$}} & 100 & 100 & 100 & 100 & 100 & 100 & 100 & 100 & 100 & 100 \\
\hline & & 0.04 & 0.46 & 49.72 & 9.18 & 0.00 & 5.11 & 0.50 & 26.31 & 0 & 14.45 \\
\hline
\end{tabular}

Çalışma alanında hakim AKAÖ tipi her iki tarih için ilçenin doğu-batı yönünde uzanan ve yüksek kesimlerde yer alan orman alanlarından oluşmaktadır. Ormanlar 2000 ve 2020 yıllarında toplam çalışma alanının sırasıyla \%44.97 ve \%43.54'ünü oluşturmaktadır. Ayrıca 2000 yılında orman olan alanlardan, 2020 yılında başta bitki örtüsü az alanlar olmak üzere, çıplak yüzey, sera alanı, yol, tarım alanı ve maden sahalarına dönüşüm yaşandığı görülmektedir. Bu dönüşümlerle birlikte, 20 yıllık zaman diliminde ormanlarda yaşanan 2517ha'lık alan kaybının yanı sıra, artan parça sayısı ve Öklid en yakın komşu mesafesi ile azalan ortalama yama alanı, orman alanlarında parçalanma ve izolasyonun arttığına işaret etmektedir. Bu sonuç önceki çalışmalarda da 
Sünbül, V. ve Tonyaloğlu Ersoy, E., Uluslararası Doğu Anadolu Fen Mühendislik ve Tasarım Dergisi / International Journal of Eastern Anatolia Science Engineering and Design (IJEASED)

(2021) 3(2): 376-387

vurgulandığı üzere, ülkemizde orman alanlarında yaşanan kayıp ve parçalanmada tarımsal üretimle birlikte maden sahası ve yol gibi yapay yüzeylerdeki artışın önemli bir etken olduğunu vurgulamaktadır (Nayim ve Uzun, 2018; Yazgan, 2018; Kesgin Atak, 2020; Kurtşan ve Nurlu, 2020).

Çalışma alanında ormanlardan sonra en yaygın AKAÖ bitki örtüsü az alanlardan oluşmaktadır. Bitki örtüsü az alanlar genellikle orman, sera alanı ve yapay yüzeylerin kıyılarında yer almaktadır. 2000 ve 2020 yılları arasında bitki örtüsü az alanlar toplam 9,187.62ha azalmıştır. Azalan parça sayısı, Öklid en yakın komşu mesafesi bitki örtüsü az alanlarda azalan izolasyon ve parçalılığa işaret etmektedir. Her ne kadar ortalama yama alanında düşüş yaşansa da bu durum toplam alandan kayıp ile ilişkilendirilmiştir. 2020 yılında bitki örtüsü az alanların \%73.69’unda dönüşüm olmazken, bitki örtüsü az alanların \%12.72'si sera alanlarına, \%10.06'sı ise çıplak yüzeylere dönüşmüştür. $\mathrm{Bu}$ durum az da olsa bitki örtüsü ile kaplı alanlarda ciddi bir kayıp yaşandığını göstermektedir. Ayrıca her ne kadar iyileşme görülen ve ormanlara dönüşen alanlar var olsa da, yapay yüzeyler ile maden sahalarına dönüşümünde bitki örtüsü az alanlarda yaşandığ 1 görülmektedir.

2020 yılında çıplak yüzeyler ile sera alanları toplam çalışma alanının sırasıyla \%14.64 ve \%13'ünü kaplamaktadır. Çıplak yüzeylerde sadece \%1,86’lık bir artış yaşanırken, sera alanları yaklaşık 3 kat artarak çalışma alanında hakimiyet kazanmaya başlamıştır. Diğer yandan artan ortalama yama alanı ve azalan parça sayısı bu AKAÖ tiplerinde azalan izolasyon ve parçalanmaya işaret etmektedir. 2000-2020 yılları arasında mevcut sera alanlarından sadece az miktarda tarım alanlarına dönüşüm yaşanırken, çıplak yüzeylerden özellikle sera, tarım ve orman alanlarına dönüşümler yaşanmıştır. Çalışmanın en önemli bulgularından birisi de tarım alanlarında meydana gelen azalmadır. 2000-2020 yılları arasında tarım alanlarında neredeyse yarı yarıya bir azalma meydana gelmiş, mevcut tarım alanlarının ortalama yama alanları ve yama sayıları da azalmıştır. 2000 yılında mevcut tarım alanlarının sadece \%50.28'i 2020 yılında görülürken, \%48.43'lük tarım alanı sera üretimine tahsis edilmiştir. Bu durum ekonomik açıdan Kaş ilçesinde artan sera üretiminin önemini vurgulamaktadır (Emekli vd., 2008; Benliay ve Başal, 2010).

Çalışma alanında bulunan yollar ise 2000-2020 yılları arasında 317.03ha artmıştır. Parça sayısı ve ortalama yama alanında çok büyük bir değişim olmamakla birlikte, azalan Öklid en yakın komşu mesafesi 2020 yılında yolların daha bütünleşik ve bağlantılı bir hal aldığını göstermektedir. Yerleşim alanları ile birlikte diğer ticari ve üretime ilişkin kullanımları da içinde barındıran yapısal alanların toplam alanı 2000-2020 yılları arasında yaklaşık 2 kat artarak 473.45ha'dan 1079.42ha'a 
yükselmiştir. Parça sayısındaki azalma ve ortalama yama alanındaki artış yapısal alanların çalışma alanı genelinde artışa geçtiğini ve daha az parçalı bir yapı sergilediğine işaret etmektedir. Diğer yandan azalan Öklid en yakın komşu mesafesinde görülen artış ise yapısal alanların çeperlerinde genişlemenin yanı sıra çalışma alanında yeni yapısal alanların da oluşmaya başladığını göstermektedir. Yeni oluşan yapısal alanlar ise bitki örtüsü az alanlardan bu alanlara dönüşüm şeklinde yaşanmıştır.

2000 yılında çalışma alanında benzer toplam alana sahip olan liman ve maden sahası AKAÖ tipleri, 2020 yılında sırasıyla 2 ve 4 kat artış göstermiştir. Her ne kadar bu AKAÖ tipleri çalışma alanı toplam alanı dikkate alındığında çok büyük alansal yayılıma sahip olmasa da, özellikle maaden sahalarında yaşanan yaklaşık 4 kat artış dikkat çekicidir. Maden sahalarına dönüşüm büyük oranda orman ve bitki örtüsü az alanlarda yaşandığ olumsuz etki yaratabileceği düşünülmektedir. Son olarak su yüzeylerinde ise 20 ylllık dönemde herhangi bir değişim ve dönüşüm yaşanmamıştır.

\section{Sonuçlar ve Öneriler}

Peyzaj yapısı ve içinde bulundurduğu AKAÖ deseni, peyzajların önemli bir özelliğini oluşturmakta ve peyzaj ekolojisinde temelli birçok çalışma, peyzaj yapısını sayısal verilerle irdeleyerek AKAÖ deseni, temel peyzaj işlevleri ve değişimi arasındaki ilişkileri değerlendirmeyi içermektedir (Uy ve Nakagoshi, 2007). Bu çalışmaların önemli bir bölümünde kentsel alanlarda veya insan etkisinin yoğun olduğu alanlarda gerçekleştirilmiş ve genellikle zaman serisi UA verileri, CBS ve peyzaj metrikleri kullanılarak peyzaj yapısındaki değişikliklerin araştırılmasının önemine vurgu yapılmıştır (Herold ve ark., 2002). Buna ek olarak, peyzaj ve AKAÖ analiz edilip değerlendirilmesi, farklı arazi yönetimi seçeneklerinin potansiyel ekolojik etkilerini belirleyebilmek, sürdürülebilir gelişme için uygun kararların alınabilmesi ve çeşitli yaban türlerinin ekolojik gereksinimleri ile peyzajların mekansal özellikleri arasındaki ilişkileri anlamak için temel bilgiler sağlamaktadır (Bender ve ark., 2003; Kesgin Atak, 2020). Bu çalışmada Türkiye'nin önemli turizm ve tarımsal üretim alanlarından birisi olan Antalya ili, Kaş ilçesinde 2000-2020 yılları arasında meydana gelen değişim ve dönüşümler incelenmiştir. Çalışma alanında görülen en önesmli değişim ve dönüşümler kıyı alanlarında yapısal alanlar, sera alanları ve maden sahalarında meydana gelen artışlar ve tarım alanları ve bitki örtüsü az alanlardan kayıplar şeklinde yaşanmıştır. Yerleşim alanları ile birlikte diğer ticari ve üretime ilişkin kullanımları da içinde barındıran yapısal alanlar 
daha çok kıyılara yakın bölgelerde artış ve yayılım gösterirken, sera üretiminin çalışma alanında önemli bir ekonomik kaynak olarak kullanılmaya başlandığı tespit edilmiştir.

Tarım alanları genellikle doğal peyzaj elemanları ve biyoçeşitlilik üzerinde olumsuz etkilere sahip önemli bir insan kaynaklı tehdit olarak değerlendirilmektedir (Kerbiriou ve ark., 2018). Buna karşın, temel ekonominin tarıma dayalı olduğu, yoğun tarımsal üretim yapılan alanlarda özellikle tarla sınırlarında yer alan doğal vejetasyon koridorları biyoçeşitliliğin desteklenmesi ve korunması açısından büyük önem taşımaktadır (Lacoeuilhe ve ark., 2018; Tonyaloğlu Ersoy ve Kesgin Atak, 2019). Bu kapsamda tarım alanlarından sera alanına dönüştürülen yaklaşık 8200ha'lık alanda tarla sınırlarında yer alan doğal vejetasyon koridorlarının da zarar gördügü öngörülmektedir. Ayrıca toprak ve bitkisel yüzeyin yapay malzemeler ile örtülmüş olması su kaynakları, toprak yapısı ve görsel peyzaj deseninin de olumsuz etkilenmesine neden olmaktadır (Benliay ve Başal, 2010). Bu kapsamda Benliay ve Başal (2010) ekonomik ömrünü tamamlamış olan sera alanlarında, yeniden sera üretimine yönelik iyileştirmelerin yapılması yerine gerekli toprak sslahı çalışmaları ile bahçe üretiminin desteklenmesi gerektiğini vurgulamaktadır. Ayrıca, tarımsal parseller arasında yer alan mevcut bitki örtüsü korunmalı ve gerekli alanlarda doğal vejetasyon örtüsüne ait bitki türleri ile bu alanlar yeniden oluşturulmalıdır (Tonyaloğlu Ersoy ve Kesgin Atak, 2019). Orman ve bitki örtüsü az alanlardan yapay yüzeyler, maden sahası ve sera alanlarına dönüşüm miktarı az olsa da, bu alanlar genellikle yoğun araç trafiği, erozyon, çevre ve gelecekte oluşabilecek hızlı ve yoğun peyzaj değişimi ile ilişkili olduğu bilinmektedir (Nayim ve Uzun, 2018). Özellikle kentsel yerleşimler çevresinde yer alan doğal / doğala yakın AKAÖ tiplerinin tarımsal kullanımlar ile diğer yapay yüzeylere dönüşmesi bu alanlar üzerindeki baskının artması, toprak verimliliğinin azalması, biyolojik çeşitliliğin zarar görmesi ve uzun vadede iklim değişikliği gibi sorunlara neden olmaktadır (Alberti, 2005). Bu nedenle sürdürülebilirliğin sağlanması ve peyzajın korunması için AKAÖ değişim ve dönüşümlerinin, özellikle de doğal / doğala yakın AKAÖ tiplerinde meydana gelen değişimlerin, sürekli ve düzenli aralıklarla izlenmesi gerekmektedir.

\section{Yazarların Katkısı}

Çalışmada her iki yazar da eşit oranda katkı sunmuştur.

\section{Çıkar Çatışması Beyanı}

Yazarlar arasında herhangi bir çıkar çatışması bulunmamaktadır.

\section{Araştırma ve Yayın Etiği Beyanı}


Yapılan çalışmada, araştırma ve yayın etiğine uyulmuştur.

\section{Kaynaklar}

Akman, A. D., (2007). Turizm Gelişmesinin Yarattı̆̆ Doğal ve Kültürel Değişimler: Kaş Örneği. Doktora Tezi (yayımlanmamış), Ankara Üniversitesi Sosyal Bilimler Enstitüsü, Sosyal Çevre Bilimleri Anabilim Dal, Ankara.

Alberti, M. (2005). The effects of urban patterns on ecosystem function. International Regional Science Review, 28(2), 168-192.

Atak, B. K. (2020). Analysing The Relationships Between Land Use/Land Cover and Urban Land Surface Temperature Using Regression Tree in İzmir. International Journal of Geography and Geography Education, (41), 280-291.

Bender, D. J., Tischendorf, L. and Fahrig, L. (2003). Using patch isolation metrics to predict animal movement in binary landscapes. Landscape Ecology, 18(1), 17-39.

Benliay, A. ve Başal, M. (2009). Peyzaj planı oluşturulması bağlamında Finike-Kumluca kıyı bölgesinin değerlendirilmesi. Akdeniz Üniversitesi Ziraat Fakültesi Dergisi, 23(2), 99-107.

Botequilha Leitão, A., Miller, J., Ahern, J. and McGarigal, K. (2006). Measuring landscapes. Island, Washington, DC.

Congalton, R. G. and Green, K. (2019). Assessing the accuracy of remotely sensed data: principles and practices. CRC press.

Corner, R. J., Dewan, A. M. and Chakma, S. (2014). Monitoring and prediction of land-use and land-cover (LULC) change. In Dhaka megacity. Springer, Dordrecht.

Emekli, N., Büyüktaş, D. ve Büyüktaş, K. (2008). Antalya Yöresinde Seraciliğin Mevcut Durumu ve Yapisal Sorunlari. Derim, 25(1), 26-39.

Guan, D., Li, H., Inohae, T., Su, W., Nagaie, T., Hokao, K. (2011). Modeling urban land use change by the integration of cellular automaton and Markov model. Ecological Modelling, 222(20-22), 3761-3772.

Herold, M., Scepan, J. and Clarke, K.C. (2002). The use of remote sensing and landscape metrics to describe structures and changes in urban land uses. Environment and Planning A, 34(8), 1443-1458.

Ito, S., Nakayama, R. and Buckley, G. P. (2004). Effects of previous land-use on plant species diversity in semi-natural and plantation forests in a warm-temperate region in southeastern Kyushu, Japan. Forest Ecology and Management, 196(2-3), 213-225.

Kerbiriou, C., Azam, C., Touroult, J., Marmet, J., Julien, J. F. and Pellissier, V. (2018). Common bats are more abundant within Natura 2000 areas. Biological Conservation, 217, 66-74.

Kesgin, B., Nurlu, E. (2009). Land cover changes on the coastal zone of Candarli Bay, Turkey using remotely sensed data. Environmental Monitoring and Assessment, 157(1), 89-96.

Kurtşan, K. ve Nurlu, E. (2018). Tarımsal Peyzaj Değişimi Analizi: İzmir ili Bornova İlçesi Örneği. Ege Üniversitesi Ziraat Fakültesi Dergisi, 81-89.

Lacoeuilhe, A., Machon, N., Julien, J. F. ve Kerbiriou, C. (2018). The relative effects of local and landscape characteristics of hedgerows on bats. Diversity, 10(3), 72.

Lambin, E.F., Turner, B.L., Geist, H.J., Agbola, S.B., Angelsen, A., Bruce, J.W., Coomes, O.T., Dirzo, R., Fischer, G., Folke, C. and George, P. (2001). The causes of land-use and land-cover change: moving beyond the myths. Global Environmental Change, 11(4), 261-269.

Liu, T. and Yang, X. (2015). Monitoring land changes in an urban area using satellite imagery, GIS and landscape metrics. Applied Geography, 56, 42-54.

Lu, D., Mausel, P., Brondizio, E. and Moran, E. (2004). Change detection techniques. International Journal of Remote Sensing, 25(12), 2365-2401.

Lu, D., Moran, E., Hetrick, S. and Li, G. (2011). Land-use and land-cover change detection. Advances in Environmental Remote Sensing Sensors, Algorithms, and Applications. CRC Press Taylor \& Francis Group, New York.

McGarigal, K. (1995). FRAGSTATS: spatial pattern analysis program for quantifying landscape structure (Vol. 351). US Department of Agriculture, Forest Service, Pacific Northwest Research Station. 
Sünbül, V. ve Tonyaloğlu Ersoy, E., Uluslararası Doğu Anadolu Fen Mühendislik ve Tasarım Dergisi / International Journal of Eastern Anatolia Science Engineering and Design (IJEASED)

(2021) 3(2): 376-387

Meyer, W. B. and BL Turner, I.I. (Eds.). (1994). Changes in land use and land cover: a global perspective (Vol. 4). Cambridge University Press.

Nayim, B. N., ve Uzun, F. (2018). Kentsel Gelişimin Peyzaja Etkisinin Değerlendirilmesi, Bartın Kenti Örneği. Bartın Orman Fakültesi Dergisi, 20(3), 443-452.

Tonyaloğlu, E. E. ve Atak, B. K. (2019). Delta Sistemlerinde Peyzaj Deseni ve Mekansal Bağlantılılı̆̆ın Analizi, Büyük Menderes Deltası Örneği. Adnan Menderes Üniversitesi Ziraat Fakültesi Dergisi, 16(2), 209-215.

URL-1: https://earthexplorer.usgs.gov/, (Erişim Tarihi: 5 Mart 2021).

Uy, P. D., Nakagoshi, N. (2007). Analyzing urban green space pattern and eco-network in Hanoi, Vietnam. Landscape and Ecological Engineering, 3(2), 143-157.

Wang, D., Gong, J., Chen, L., Zhang, L., Song, Y., Yue, Y. (2013). Comparative analysis of land use/cover change trajectories and their driving forces in two small watersheds in the western Loess Plateau of China. International Journal of Applied Earth Observation and Geoinformation, 21, 241-252.

Yazgan, A. (2018). İstanbul Kıyı Alanlarında İkinci Konutun Değişim ve Gelişimi. Megaron, 13(3). 